Jahreszahlen veröffentlich

\section{apoBank konzentriert sich auf das Kerngeschäft}

_ Die Deutsche Apotheker- und Ärztebank (apoBank) blickt auf das schwärzeste Jahr ihrer Geschichte zurück. 2009 hat die Bank erstmals rote Zahlen geschrieben und wird ihren Mitgliedern keine Dividende ausschütten. Mit dem Jahresabschluss 2009 hofft das Institut aber nun, die Finanzkrise verdaut zu haben.

Das abgelaufene Geschäftsjahr habe die Bank dazu genutzt, die Risiken zu identifizieren, das Portfolio an Finanzinstrumenten zu reduzieren, und umfangreiche Risikovorsorge zu treffen, so Vorstandssprecher Herbert Pfennig, der den Jahresabschluss der Bank präsentierte. Das Ergebnis dieser Strategie sei ein Jahresfehlbetrag in Höhe von 283,1 Millionen EUR nach einem Überschuss von 60 Millionen EUR im Vorjahr. Kräftig ins Kontor hat 2009 vor allem die mehr als verdoppelte Risikovorsorge geschlagen - sie stieg von 244 Millionen EUR auf gut 588 Millionen EUR. Auch die Eigenkapitalbasis der apoBank hat sich nach seinen Angaben stabilisiert.

Erfreulich sei laut Pfennig, dass das operative Geschäft der apoBank auch 2009 wieder ,sehr gut gelaufen ist“. Die Zahl der Kunden habe sich nochmals um 14.000 auf 333.000 erhöht, das Teilbetriebsergebnis vor Risikovorsorge sei das höchste in der Geschichte der Bank (317,8 Millionen EUR). Diese positive Entwicklung hat sich auch im ersten Quartal 2010 fortgesetzt. Im laufenden Jahr will die Bank wieder Gewinn machen, und die Mitglieder der Genossenschaftsbank sollen auch eine Dividende erhalten. Die apoBank wolle sich nun „ganz konsequent auf ihr Kerngeschäft fokussieren“.

\section{Bonus für Versicherte BKK-Angebot legitim}

\begin{abstract}
— Eine Betriebskrankenkasse (BKK) bot ihren Mitgliedern einen Bonus an. Sie erhielten ihn unter anderem, wenn sie Normalgewicht hatten (Body-Mass-Index zwischen 18 und 27) oder wenn sie angaben, seit mindestens sechs Monaten Nichtraucher zu sein. Ein „Spion“ der AOK Hessen rief bei der BKK an und fand im Gespräch mit einer Sachbearbeiterin heraus, dass der Bonus auch ohne ärztliche Überprüfung der Angaben gewährt wurde: „Das glauben wir den Mitgliedern so“, erklärte die Sachbearbeiterin. Daraufhin zog die AOK Hessen vor Gericht und forderte, die Konkurrenz müsse dieses wettbewerbswidrige Verhalten unterlassen. Dafür sah die BKK keinen guten Grund und verwies darauf, dass das Bundesversicherungsamt die Bonusregelung genehmigt hatte. Die Kasse dürfe daraufvertrauen, dass die schriftlichen Erklärungen ihrer Mitglieder stimmten. Ärztliche Bescheinigungen anzufordern, führte zu einem absurden bürokratischen Aufwand.

Das Landessozialgericht Hessen gab der BKK Recht (L 8 KR 294/Og B ER). Inwiefern die Bonus-Praxis wettbewerbswidrig sein könnte, sei nicht nachvollziehbar. Die Satzung der BKK schreibe keine ärztliche Bestätigung vor. Die BKK werbe auch nicht damit, dass sie die Voraussetzungen für den Bonus nur „lax“ überprüfe. Dass der AOK durch die Bonusregelung der Konkurrenz ein unzumutbarer Nachteil - zum Beispiel ein Verlust an Mitgliedern - drohe, habe die AOK nicht belegen können.
\end{abstract}

\section{Spermienzahl zu Hause messen}

\section{Neuer Test zeigt männliche Unfruchtbarkeit an}

— Nicht immer klappt es mit dem Kinderkriegen so wie gewünscht. Weltweit haben zwischen $10 \%$ und $15 \%$ aller Paare Fertilitätsprobleme. Ob das an einer geringen Spermienzahl liegt, lässt sich jetzt mit einem einfachen Test zu Hause messen. Ähnlich wie ein Schwangerschaftstest basiert der SpermTest FERTILITY auf einer immunchromatografischen Diagnostik. Je nach Anzahl der Spermien pro Milliliter Samenflüssigkeit erscheint eine gefärbte Linie. Dabei wird zwischen einer Normozoospermie (mehr als 20 Millionen Spermien $/ \mathrm{ml}$ ), einer Oligozoospermie (5-20 Millionen $/ \mathrm{ml})$ und einer starken Oligozoospermie (weniger als 5 Millionen $/ \mathrm{ml}$ ) unterschieden. Der Test basiert auf einem Antikörper gegen das Protein SP-10, das konstant auf der Oberfläche des Spermienkopfes exprimiert wird.

In einer aktuellen Studie untersuchten US-amerikanische Forscher nun, ob sich der Test zur akkuraten Messung der Spermienzahl eignet. Verglichen wurden die Ergebnisse des SpermTest FERTILITY von 225 Samenproben mit der Messung anhand eines Hämozytometers. In mehr als 96\% Fällen stimmten die beiden Messungen

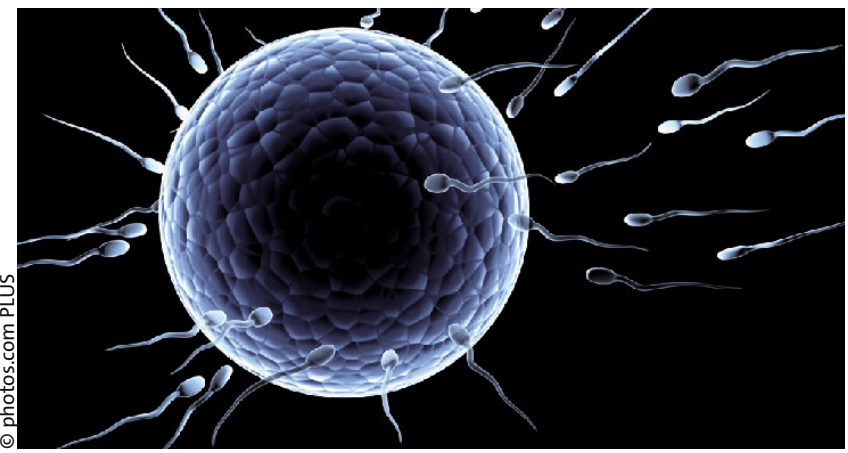

Die Spermienzahl lässt sich auch zu Hause messen.

überein. Auch zeigte die Untersuchung, dass Personen ohne Erfahrung den Test erfolgreich und korrekt anwenden können: Die Messung von 164 unerfahrenen Anwendern stimmte in 95\% der Fälle mit der Interpretation der Testergebnisse durch erfahrenes Klinikpersonal überein.

In Europa ist der Test bereits zugelassen und ermöglicht Männern, schnell und einfach zu Hause zu testen, ob ihre Spermienzahl im fruchtbaren oder unfruchtbaren Bereich liegt. Je nach Ergebnis kann ein Paar dann entscheiden, ob weitere klinische Tests notwendig sind. 